\title{
Rehabilitation of Patients with Through-knee Amputation
}

\author{
P. F. EARLY,* M.B., B.CHIR., F.R.C.S.
}

\begin{abstract}
Summary : One hundred and one patients with through-knee amputations attending the Manchester limb-fitting centre are reviewed. Most amputations were performed for trauma or vascular disease. The interval from amputation to measurement for the first prosthesis averaged 12 weeks in cases of primary healing, and 21 weeks when healing was delayed. Artificial limbs were successfully fitted to $83 \%$, and only $10 \%$ failed to use either a limb or a pylon. Three-quarters of those with outdoor mobility returned to work.

Disarticulation through the knee has several advantages over above-knee amputation : in particular, the long endbearing stump facilitates balance and control of the prosthesis. Disadvantages are a tendency to slow healing of the wound, lack of an internal knee mechanism in the artificial limb, and the bulky appearance of the limb. The results of rehabilitation could be improved by careful selection of patients and attention to operative detail; stump bandaging and exercises; earlier attendance at the limb-fitting centre to be measured for pylon or artificial limb; and improvements in design and production of prostheses.
\end{abstract}

\section{Introduction}

Disarticulation at the knee has long been recommended as an alternative to above-knee amputation, particularly in children and in the elderly : yet of all lower-limb amputees who first attended limb-fitting centres in Britain from 1958 to 1962, only $3.5 \%$ had undergone disarticulation, in contrast to $55.6 \%$ with amputations through the thigh-a ratio of $1: 16$. It is probable that through-knee amputation would have been surgically feasible in a much higher proportion; should, then, a wider use of this amputation be encouraged, in the light of the patients' progress through limb-fitting and rehabilitation?

The present paper is based on a study of 106 through-knee amputees first seen at the Manchester limb-fitting centre during the years 1957-65 (Table I). These represent $3.6 \%$ of the 2,967 lower-limb amputees seen in that period. All surviving patients were followed up for two years or more.

TABLB I.-Through-knee Amputees First Attending Manchester Limbfitting Centre, 1957 to 1965 . The Sudden Increase During 1965 wa Maintained Through 1966 and 1967 (24 New Cases Each Year)

\begin{tabular}{l|c|c|c|c|c|c|c|c|c}
\hline Year & \\
No. of cases .. & 1957 & 1958 & 1959 & 1960 & 1961 & 1962 & 1963 & 1964 & 1965 \\
\hline
\end{tabular}

One problem in fitting a through-knee amputation stump is that the presence of the lower end of the femur makes it diffcult to incorporate an internal knee-control mechanism in the artificial limb. In 5 of the 106 patients, however, the stump was short enough (by comparison with the opposite thigh) to be fitted with an artificial limb of the above-knee type. Shortening was due in one case to congenital defect and in the others to Interference with growth of the femur by injury or disease ; these five patients, being equivalent to above-knee amputees, are excluded from further analysis.

- Sentor Medical Officer, Ministry of Health Limb Fitting Service, Manchester.

\section{Reasons for Amputation}

The reasons for amputation are shown in Table II. Most amputations in the younger group followed accidents on the road or at work, whereas those in older patients were performed mainly for arteriosclerotic or diabetic gangrene and other vascular disorders. Among the other causes were poliomyelitis (seven cases) and malignancy (six cases). There were eight bilateral through-knee amputees (including the five children with congenital deformities) and seven patients with either aboveknee or below-knee amputation of the other leg.

TABLE II.-Reasons for Amputation

\begin{tabular}{|c|c|c|c|c|c|}
\hline & \multicolumn{4}{|c|}{ Age at Amputation } & \multirow{3}{*}{ Total } \\
\hline & \multicolumn{2}{|c|}{ Under 50} & \multicolumn{2}{|c|}{50 and Over } & \\
\hline & Male & Female & Male & Female & \\
\hline $\begin{array}{ll}\text { Congenital anomalies } \\
\text { Trauma } \\
\text { Vascular disease } & \text {.. } \\
\text { Other causes } & \text {.. }\end{array}$ & $\begin{array}{r}1 \\
19 \\
3 \\
7\end{array}$ & $\begin{array}{l}4 \\
1 \\
0 \\
2\end{array}$ & $\begin{array}{r}0 \\
9 \\
30 \\
4\end{array}$ & $\begin{array}{r}0 \\
0 \\
17 \\
4\end{array}$ & $\begin{array}{r}5 \\
29 \\
50 \\
17\end{array}$ \\
\hline Total & 30 & 7 & 43 & 21 & 101 \\
\hline
\end{tabular}

\section{From Hospital to Limb Centre}

After amputation, how long did it take a patient to reach the limb-fitting centre? This period could be prolonged by other injuries or illness, or by delayed healing of the stump, but even with primary healing the time ranged from 4 to 29 weeks, and averaged 12 weeks. Where healing was delayed the average rose to 19 weeks, with a further two weeks before measurements for a prosthesis could be taken. Thus the supply of a pylon or artificial limb was put back by as much as nine weeks, on average, because of slowness in wound healing.

\section{Delayed Healing of Stump}

Typically the delay in healing of the stump takes the form of a breakdown along part of the posterior suture line; the skin edges separate and the raw area heals by granulation. Healing was slow in 36 patients-in 15 the stump was still discharging at their first visit to the limb-fitting centre. Table III shows that delay most of ten occurred after amputations for trauma and for vascular disease, and was significantly less frequent in other cases. Common causes were wound infection and skin shortage (with overstretching of the flaps, or the need for grafting) in traumatic amputations, and ischaemia of the long anterior flap in cases of vascular disease. Only one patient (a tabetic with Charcot's knee joints) is known to have needed reamputation, owing to repeated breakdown of the stump.

Should the Patella be Removed?-It has been suggested that removal of the patella, by reducing the bulk of the stump, facilitates skin closure; on the other hand, its removal prolongs

TABLE III.-Incidence of Delayed Healing

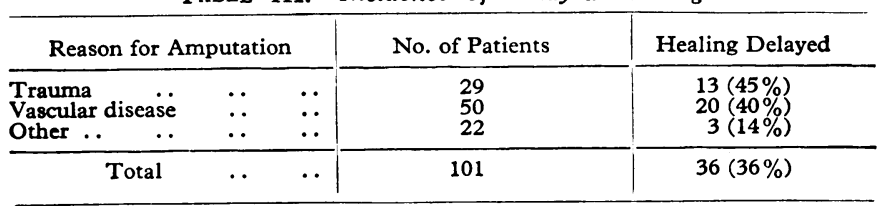


the operation, may interfere with the blood supply to the anterior flap, and decreases the area of weight-bearing (Vitali and Harris, 1964). The patella had been removed or retained in about equal numbers of our patients, and no significant difference in rate of healing was found between the two groups. From the limb-fitting angle it is an advantage to retain the patella, the patellar ligament and hamstrings being sutured to the cruciate ligaments in the intercondylar notch.

\section{The Prosthesis}

Once the stump is healed, and post-operative oedema reduced by firm binding with a crêpe or Rayolast bandage and by stump exercises, the patient can be measured for an artificial limb (Fig. 1). The limb commonly used-and supplied to 62 of

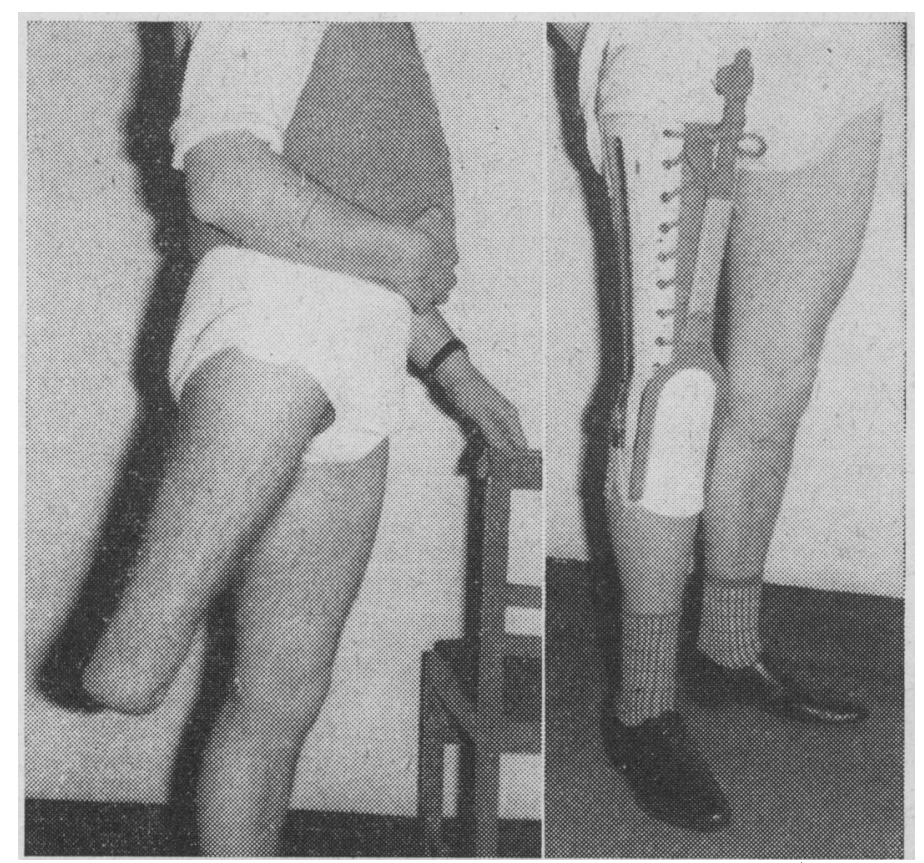

FIG. 1.-Through-knee stump and artificial limb. Amputation following motor-cycle accident; fractured patella was excised.

the 101 patients in this series (Table IV)-has a leather lacing socket, shaped from a cast of the stump. The socket opens down its front to admit the bulbous end of the stump, which bears on a sponge-rubber pad in the lower end of the socket. The socket is connected through side-steels and ball-bearing joints to the light metal (or fibreglass) shin (Fig. 2A). A ringcatch knee lock may be fitted for elderly patients of poor physique, or if the stump is weak-for example, following poliomyelitis. This was done in 47 cases, though seven of these patients were able to walk on level ground with the knee unlocked. The limb is suspended from a shoulder-brace or waist-belt, attached to the socket behind and through a forked strap to the top of the shin in front; but some amputees do without any support other than the socket itself.

TABLE IV.-Types of Prosthesis Fitted

\begin{tabular}{|c|c|c|c|c|c|}
\hline & & & & $\begin{array}{c}\text { As Primary } \\
\text { Limb }\end{array}$ & $\begin{array}{l}\text { Preceded by } \\
\text { Pylon }\end{array}$ \\
\hline Metal limb & $\begin{array}{l}\text { Leather socket } \\
\text { Leather tuber-bearing s } \\
\text { Metal socket } \\
\text { Metal H-socket } \\
\end{array}$ & $\begin{array}{l}\text { socket } \\
\because . \\
.\end{array}$ & $\because \ddot{.}$ & $\begin{array}{r}48 \\
5 \\
2 \\
2 \\
\end{array}$ & $\begin{array}{r}14 \\
2 \\
1 \\
8 \\
\end{array}$ \\
\hline Wood limb \{ & $\begin{array}{l}\text { Wood socket } \ldots \\
\text { Wood H-socket .. }\end{array}$ & $\because$. & $\ddot{.}$ & 1 & $\begin{array}{l}3 \\
2 \\
\end{array}$ \\
\hline \multicolumn{2}{|c|}{ 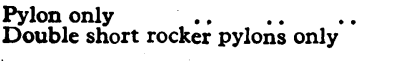 } & $\because$ & $\because$ & \multicolumn{2}{|c|}{$\begin{array}{l}8 \\
5\end{array}$} \\
\hline
\end{tabular}

If the stump will not tolerate full end-bearing, because of extensive scarring for example, a socket is made that will carry part or all of the patient's weight through the ischial tuberosity. For partial ischial bearing a leather or conventional metal

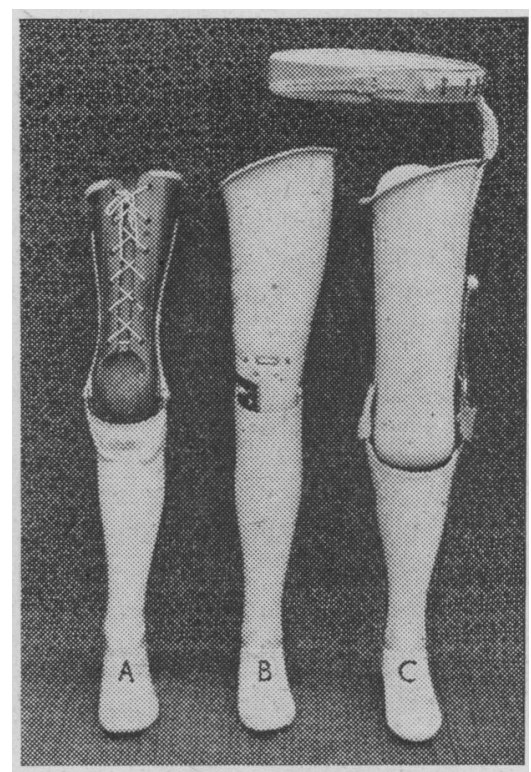

FIG. 2.-(A) Standard limb for throughknee amputee, with leather socket. (B) Above-knee limb for comparison (windowed to show Blatchford stabilized knee $\begin{array}{ll}\text { dowed to show Blatchrord stabilized knee } & \text { (C) Through-knee limb with }\end{array}$ metal socket (H-type). Note the pelvic band and knee lock.

socket suffices; but for full ischial bearing a metal H-socket (with its positive tuber-seat) is more satisfactory. As a metal socket must be wide enough to admit the bulbous stump, the appearance of such a limb is ungainly (Fig. 2C). Of the 88 patients supplied with artificial limbs, $22(25 \%)$ were unable to take full end-bearing. Young children, once past the pylon stage, are generally given wood limbs, which are relatively light and can easily be adjusted to growth of the child.

In 17 cases a pelvic band was added to assist control of the limb. Thus weakness or paralysis of hip muscles may cause the limb to abduct or rotate ("toe-in"); a rigid pelvic band checks this tendency by allowing the hip joint to move only in the sagittal plane.

Pylons.-Forty-three patients were supplied in the first instance with a rocker-based pylon or a pair of short pyloss (Table IV). Most were later given full artificial limbs, but three children went through an intermediate stage wearing pylons with feet (Fig. 3). Ten adults (of average age 75), through debility or being double amputees, had pylons only, and three others died before a limb could be fitted. The reasons for fitting pylons in these $\mathbf{4 3}$ cases were: delayed stump healing (10), old age or other disabilities (16), bilateral amputationchildren (4), bilateral amputation-adults (7), and earlier ambulation (6). The pylon, having an open-ended socket with full ischial bearing, can be used when the stump is still unhealed or has tender adherent scars: in other cases an endbearing pad may be added (Fig. 4). Its lightness is an advantage to many patients in the early stages. The sooner a pylun is fitted the more readily will the patient regain his sense of balance, and training a patient to walk on the artificial limb will be easier if he has already used a pylon.

Walking Instruction.-This was given either in the walkingtraining school of the limb-fitting centre or at the patient's local hospital. The limb fitted with a knee lock presents little problem. A free knee, however, requires the amputee, at the end of the forward swing, to strike the heel firmly on the ground and keep the stump pressed backwards during the stance 
(weight-bearing) phase, in order to stabilize the knee in extension. As the natural leg assumes weight-bearing the artificial leg is swung forward, allowing the knee to flex (Fig. 5).

\section{Results of Limb Fitting}

\section{Walking Ability}

All patients fitted with artificial limbs were divided into four grades (Table V). Those in grade $\mathbf{A}$ could walk at least several hundred yards at a stretch, one-half of them as far as two to three miles (3.2 to $4.8 \mathrm{~km}$.). One young man claimed to be able to go 15 to 20 miles ( 24 to $32 \mathrm{~km}$.) in cool weather. Grade B patients were able to walk short distances out-of-doors, being limited by chest complaints (angina, bronchitis), claudication in the natural leg, or simply by old age. Patients in grade $\mathrm{C}$ could get about the house and perhaps potter around the garden, independently of others; while grade D included those who had attempted but abandoned limb-wearing. The walking capacity of the 13 pylon-wearers, shown in Table V, corresponded to grade $\mathbf{A}$ in one case, to grade $\mathrm{B}$ in three cases, to grade $C$ in three cases, and to grade $D$ in six cases. It will be seen that 84 patients $(83 \%)$ benefited from wearing full artificial limbs, and only 10 failed entirely to make use of any kind of prosthesis.

TABLE V.-Result of Limb Fitting

\begin{tabular}{|c|c|c|c|}
\hline Walking Ability & Male & Female & Total \\
\hline $\begin{array}{l}\text { Grade A-good } \\
\text { Grade B-limited outdoor } \ldots \\
\text { Grade C-independent indoor } \\
\text { Grade D-limb-wearing abandoned } \\
\text { Pylons only }\end{array}$ & $\begin{array}{r}31 \\
22 \\
12 \\
2 \\
6\end{array}$ & $\begin{array}{r}4 \\
5 \\
10 \\
2 \\
7\end{array}$ & $\begin{array}{r}35 \\
27 \\
22 \\
4 \\
13\end{array}$ \\
\hline Total $\quad .$. & 73 & 28 & 101 \\
\hline
\end{tabular}

Table VI shows how certain factors are related to the walking ability of those amputees who were fitted with artificial limbs. The average age at amputation, the percentage of amputations due to vascular disease, the proportion of patients with other disabilities and of those requiring knee locks, all increase as the walking capacity diminishes. Of the five double amputees in grade A four were children.

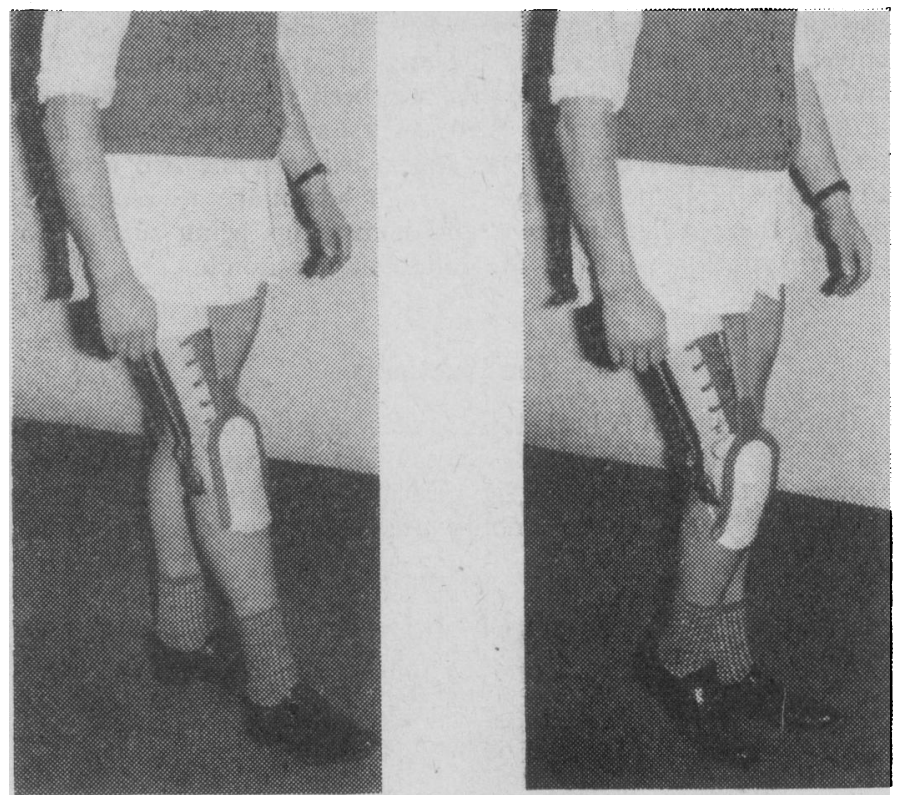

FIG. 5.-Stages in walking with a free-swinging knee.

TABLE VI.-Factors Related to Walking Ability

\begin{tabular}{|c|c|c|c|c|}
\hline & \multicolumn{4}{|c|}{ Grade of Walking Ability } \\
\hline & $\mathbf{A}$ & B & C & $\mathbf{D}$ \\
\hline No. of patients in each grade $\ldots$ & 35 & 27 & 22 & 4 \\
\hline $\begin{array}{l}\text { Average age (years) } \\
\text { Amputations for vascular disease } \\
\text { Double amputees } \\
\text { Patients with other disabilities } \\
\text { Limbs fitted with knee locks }\end{array}$ & $\begin{array}{l}33 \\
5(14 \%) \\
5(14 \%) \\
2(6 \%) \\
6(17 \%)\end{array}$ & $\begin{array}{l}54 \\
15(56 \%) \\
2(7 \%) \\
15(56 \%) \\
16(59 \%)\end{array}$ & $\begin{array}{l}71 \\
14(64 \%) \\
1(5 \%) \\
18(82 \%) \\
21(95 \%)\end{array}$ & $\begin{array}{l}\quad 63 \\
4(100 \%) \\
2(50 \%) \\
4(100 \%) \\
4(100 \%)\end{array}$ \\
\hline
\end{tabular}

\section{Return to Work}

Excluding those who had already retired before amputation or were not employed (children, housewives), $82 \%$ of patients in grade $A$ and $60 \%$ of those in grade $B$ returned to work of some kind (Table VII). Two young amputees in grade $\mathrm{A}$ died of malignancy before completing their rehabilitation. Of the nine others in grades $\mathrm{A}$ and $\mathrm{B}$ who did not resume work, five

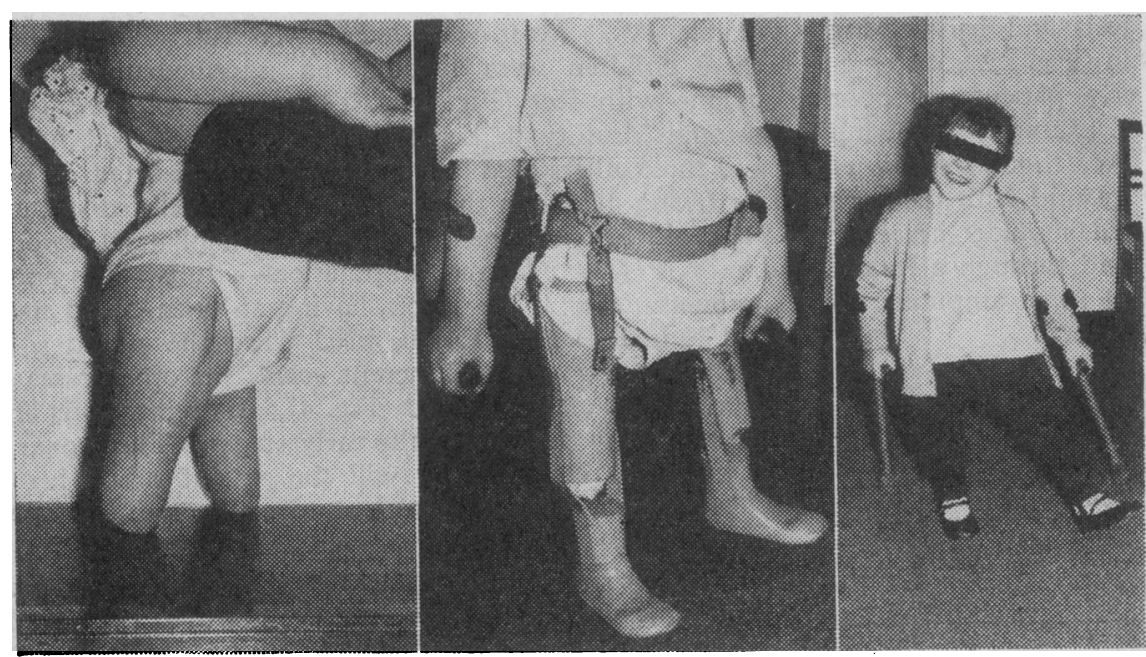

Fig. 3.-Girl aged 6 wearing pylons with artificial feet. A case of myodystrophia foetalis affecting lower limbs; bilateral through-knee amputation at age of 3 . Surgical correction of hip flexion contractures. (Mr. D. A. Richmond's case.)

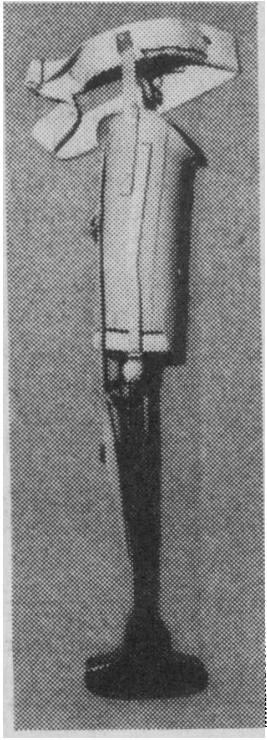

FIG. 4.-Temporary pylon, with endthrough-knee stump. 
were already aged 55 or over at the time of amputation. Two of the four younger patients had serious upper-limb disabilities from their original accidents, one had not worked for several years because of severe bilateral claudication, and one suffered a cardiac infarct eight months after amputation.

TABLE VII.-Return to Work After Limb Fitting

\begin{tabular}{|c|c|c|c|c|c|}
\hline & \multicolumn{4}{|c|}{ Grade } & \multirow{2}{*}{ Total } \\
\hline & $\mathbf{A}$ & B & $\mathbf{C}$ & D & \\
\hline No. of patients ... & 35 & 27 & 22 & 4 & 88 \\
\hline $\begin{array}{l}\text { Retired or not employed before } \\
\text { amputation } \ldots \text {. } \\
\text { Employed before amputation } . .\end{array}$ & $\begin{array}{r}8 \\
27\end{array}$ & $\begin{array}{l}12 \\
15\end{array}$ & $\begin{array}{r}18 \\
4\end{array}$ & $\begin{array}{l}1 \\
3\end{array}$ & $\begin{array}{l}39 \\
49\end{array}$ \\
\hline $\begin{array}{l}\text { (1) Returned to same or similar } \\
\text { work } \\
\text { (2) Returned to less active work } \\
\text { (3) Not returned to work }\end{array}$ & $\begin{array}{l}8(30 \%) \\
14(52 \%) \\
5^{*}(18 \%)\end{array}$ & $\begin{array}{l}1(7 \%) \\
8(53 \%) \\
6(40 \%)\end{array}$ & $\begin{array}{l}\mathbf{0} \\
\mathbf{1} \\
\mathbf{3}\end{array}$ & $\begin{array}{l}\mathbf{0} \\
\mathbf{0} \\
\mathbf{3}\end{array}$ & $\begin{array}{r}9(18 \%) \\
23(47 \%) \\
17(35 \%)\end{array}$ \\
\hline
\end{tabular}

\section{Discussion}

Through-knee disarticulation has certain advantages over amputation through the thigh (Gillis, 1954, 1964 ; Kelham, 1957):

(1) The operation is relatively bloodless, and less liable to postoperative haematoma than are higher amputations involving division of muscle bellies.

(2) Since the thigh muscles (in particular the extensors and adductors of the hip) are preserved there is little tendency for flexion or abduction contractures to develop in the stump. Only two patients among the present series showed such deformities-a child (Fig. 3) in whom bilateral $30^{\circ}$ flexion contractures were corrected by muscle-release operations, and a man aged 49 whose hip contracture was part of his long-standing rheumatoid arthritis.

(3) The long stump forms a powerful lever to activate the artificial limb.

(4) The stump is naturally suited to transmit the patient's weight to the artificial limb through the femoral condyles. Improved proprioception aids the patient's balance and control over the limb-an important consideration in the elderly or blind. End-bearing also frees the hip region and reduces the likelihood of " roll of flesh" or such complications as epidermoid cysts and abscesses developing in the adductor area of the thigh.

(5) The bulbous lower end of the stump helps to keep it in the socket of the artificial limb, and in some cases no other suspension is needed.

(6) Retention of the lower femoral epiphysis in children allows the stump to go on growing, but at a reduced rate, so that by the end of the growth period the patient may have a stump which can be fitted into an above-knee type of prosthesis and which at the same time will tolerate end-bearing.

The disadvantages of through-knee amputation are surgical and prosthetic. The main surgical drawback is the frequency of delayed healing, commonly due to ischaemic necrosis of the anterior flap. To avoid this it has been suggested that (1) the posterior skin flap should be cut as long as possible without bringing the suture line on to the weight-bearing area-thus the anterior flap can be made correspondingly shorter; and (2) when dissecting the anterior flap from the tibial tubercle, skin and patellar ligament are reflected together, keeping the dissection close to bone to avoid disturbing the blood supply to this flap (Ministry of Health, 1966).

Prosthetic disadvantages are twofold. (1) Since the artificial limb lacks a knee-control mechanism (due to the presence of the femoral condyles) these patients find it harder to develop a natural gait than do above-knee amputees wearing a limb with adjustable friction control or with the newer stabilized knee device. It should, however, be remembered that a knee lock is available if needed, and that a high proportion of elderly above-knee amputees also depend on a knee lock for stability when walking. (2) The bulky appearance of the through-knee prosthesis, in contrast with the streamlined effect of an aboveknee limb (Fig. 2B), must be taken into account when deciding the level of amputation in women.

Owing to the various factors involved in the choice of amputation site by individual surgeons, no attempt is made, in this retrospective survey, to draw a statistical comparison between through-knee and above-knee amputation. Nevertheless, the results in the present series would seem to justify a more frequent use of through-knee amputation, at least in certain groups - for example, elderly patients, younger males, and children. While primary healing of the wound is of first importance there are, besides, a number of ways in which the period of rehabilitation of these amputees could be shortened and their walking ability improved.

(1) Fitness of patient and stump is maintained by preoperative and postoperative physiotherapy, and by stump bandaging and exercises (Humm, 1965).

(2) Early reference to the limb-fitting centre-the patient should be sent as soon as the wound is healed, and in uncomplicated cases not later than four weeks from the date of amputation. This is the joint responsibility of the staffs of hospital and limb centre.

(3) Pylons (which can now be supplied in a few days) are more and more being used to get patients walking sooner, thereby shortening their stay in hospital. Pylons have been fitted as early as two weeks after amputation (Harris, 1967) and by the more specialized technique of immediate postoperative fitting (Vitali and Redhead, 1967).

(4) New techniques of assembling artificial limbs, applied to through-knee prostheses, would enable them also to be fitted much sooner than at present. External knee-control mechanisms are being developed, and a hydropneumatic swingphase control is already in use in the United States (Mazet and Hennessy, 1966).

I thank Sir George Godber, Chief Medical Officer, Ministry of Health, for permission to publish this paper. I am grateful to $\mathrm{Dr}$ D. W. Jolly, Principal Medical Officer, for his encouragement and valuable comments, and to my colleagues in the Limb Fitting Service for their help.

\section{REFERENCES}

Gillis, L. (1954). Amputations, p. 60. London.

Gillis, L. (1964). Practitioner, 193, 626.

Harris, E. E. (1967). Ann. roy. Coll. Surg. Engl., 40, 266.

Humm, W. (1965). Rehabilitation of the Lower Limb Amputee. London.

Kelham, R. D. L. (1957). Artificial Limbs in the Rehabilitation of the Disabled, p. 84. H.M.S.O., London.

Mazet, R., and Hennessy, C. A. (1966). F. Bone ft Surg., 48A, 126.

Ministry of Health (1966). Research Department, Limb Fitting Centre, Roehampton. Progress Report, No. 6, $\mathrm{p}, 2$

Vitali, M., and Harris, E. E. (1964). Clin. Orthop., 37, 61.

Vitali, M., and Redhead, R. G. (1967). Ann. roy. Coll. Surg. Engl., 